\title{
Numerical Simulation of the Phase Transformations in Steels: A Case Study on Newly-Developed Multi-Phase Steels for Drop Forgings
}

\author{
Anna Wojtacha ${ }^{1}$, Marek Opiela $^{1 *}$ \\ 1 Faculty of Mechanical Engineering, Silesian University of Technology, ul. Konarskiego 18A, 44-100 Gliwice, \\ Poland \\ * Corresponding author's e-mail: marek.opiela@polsl.pl
}

\begin{abstract}
The aim of the work was to determine the diagrams of phase evolution under equilibrium conditions and numerical simulation of austenite phase transformations under non-equilibrium conditions, as well as to determine CCT (Continuous Cooling Transformation) and TTT (Temperature Time Transformation) diagrams with the use of JMatPro software. The subject of the analysis were two newly elaborated multiphase steels assigned for production of forgings: steel A, containing of $0.165 \% \mathrm{C}, 2 \% \mathrm{Mn}, 1.11 \% \mathrm{Si}$ and steel B, containing $0.175 \% \mathrm{C}, 1,87 \% \mathrm{Mn}, 1 \%$ $\mathrm{Si}, 0.22 \% \mathrm{Mo}$ and Ti and $\mathrm{V}$ microadditions at a concentration of $0.031 \%$ and $0.022 \%$, respectively. The performed simulation revealed that the investigated steels have similar critical temperatures under equilibrium conditions: $\mathrm{A}_{\mathrm{c} 1} \sim 680^{\circ} \mathrm{C}, \mathrm{A}_{\mathrm{c} 3} \sim 830^{\circ} \mathrm{C}$. The chemical composition of steel $\mathrm{B}$ and the interaction of Mo, Ti and $\mathrm{V}$ in particular, determine that diffusion transformations, i.e. ferritic and pearlitic, in the elaborated CCT and TTT diagrams are significantly shifted to longer times in relation to the position of these transformations in the diagrams for steel A. A distinct delay also concerns the bainitic transformation. Moreover, it was found that the $\mathrm{M}_{\mathrm{S}}$ temperature of steel $\mathrm{B}$ is slightly lower. The determined CCT and TTT diagrams are essentially helpful in the development of heat and thermo-mechanical treatment conditions for new steel grades.
\end{abstract}

Keywords: numerical simulation, CCT diagram, TTT diagram, multi-phase steels

\section{INTRODUCTION}

In recent years, there has been a distinct progress in the field of methods and tools which enable the modelling and simulation of manufacturing processes, processing and shaping the microstructure as well as the mechanical properties of engineering materials. Computer aided calculations used both in scientific research and in the industrial practice, create an opportunity to significantly reduce costs by decreasing the quantity of necessary experiments. In this context, the possibility to model phase transformations and determine the CCT and TTT diagrams becomes crucial, which is principally important for newly elaborated steel grades. There are two areas that can be identified in the modelling of austenite transformations. The first is related to the description of the course of austenite transformations during cooling, while the second one - includes calculation of transformation temperature, hardness and the fraction of structural components. The models, based mainly on the Johnson-Mehl-Avrami [1, 17] and Koistinen [23] equations, allow calculating the volume fraction of the transformation product at a given temperature. Thermodynamic models are of great importance [4, 21].

There are numerous literature reports on phase transformations in steel, but only their small part concerns the calculation of the CCT and TTT curves $[8,14,26,30]$. Pioneering works in this field, published by Kirkaldy et al. [18-20], revealed the possibility to calculate precise curves of phase transformations for low-alloy steels. A slightly different methodology for determining the curves of austenite transformations was proposed by Bhadeshia in [2-4], where he examined the developed model and compared the obtained 
curves with those acquired on the basis of the experiment. The model of Bhadeshia has been extended by Lee [24] so that it was also acceptable for the steels with higher concentration of elements. Nowadays, owing to the use of thermodynamic models, it is possible to determine the phase transformations curves for different groups of steels, with high accuracy. New models keep being proposed, based both on considerations and methods using empirical data, which can be applied in a wide range of mass concentrations of elements or are dedicated to a specific group of steels. It should be taken into consideration that each modelling method requires the access to the database, which is necessary when calculating the parameters of the model and during its verification $[5,16,29,38,39,42]$.

Application of multiphase steels with retained austenite for forgings is a response to the current demand of the automotive industry. Forgings of these steels meet the quality requirements in a wide range and combine high strength, crack resistance and fatigue strength. This is indicated by the works carried out in recent years, mainly in German [13, 18] and Japanese [32-35] centres. A distinctive characteristic of these steels is the presence of plastic retained austenite, which is possible through its stabilisation with increased concentration of $\mathrm{C}$, several-stage heat treatment, and the presence of $\mathrm{Si}$, which delays precipitation of cementite in bainitic ferrite. Despite the performed research, the optimal conditions for hot working and the temperature-time profiles of several-stage cooling, ensuring combination of all the aforementioned properties, have not been developed yet.

Acquiring a desired multiphase microstructure with proper fractions of individual components, which determines obtaining optimal set of mechanical properties, requires the knowledge of the austenite transformations diagrams. Hence, the aim of this study was to determine the phase evolution diagrams under equilibrium conditions and numerical simulation of the austenite phase transformations as well as determination of the CCT and TTT curves for the newly elaborated multiphase steels.

\section{MATERIALS AND METHODS}

Chemical composition of tested steels (Table 1) was developed in terms of the possibility to produce multiphase forgings with retained austenite.

The ingots were melted in a VEM I20 electric induction furnace with a corundum lining. The metal charge, Armco iron sheets, was melted with a strictly defined addition of carburizer in a form of synthetic graphite, FeSi75A ferroalloy and pure Mn (steel A), and in the case of steel B - pure Mo, Ti and $\mathrm{V}$. Pouring temperature of molten steel was measured each time using a Pt-PtRh10 thermocouple with the DIGILANCE IV sensor from HARAEUS ELECTRO-NITE. The pouring temperature in the case of steel A was equal to $1672^{\circ} \mathrm{C}$, and $1650^{\circ} \mathrm{C}$ in the case of steel B. The method of top pouring of sand moulds, made of self-hardening moulding mass on a quartz sand matrix with a furan resin binder, was used in the steel casting process. Ingots with a diameter of $30 \mathrm{~mm}$ and a length of $400 \mathrm{~mm}$ were produced using the described method. The chemical composition of the prepared steel ingots was determined with the use of the LECO GDS500A glow discharge optical emission spectrometer.

The analysed steels have a similar carbon content $(0.165 \%$ and $0.175 \%$ - steel $\mathrm{A}$ and $\mathrm{B}$, respectively), and the concentration of $\mathrm{Mn}$, due to its solution hardening, increase in hardenability and austenite-forming effect, is equal approx. $2 \%$. Si is essential for stabilisation of the retained austenite in the examined steels. This element is not soluble in cementite, what usually occurs during bainitic transformation [7, 9]. Similar effect can be noted also for aluminium. In the case of the presence of $\mathrm{Si}$ and/or Al, precipitation of carbides does not occur during bainitic transformation - carbon diffuses to austenite, favouring its thermal stabilisation [10, $36,37]$. In order to further strengthen and lead to refinement of microstructure [12,28], an addition of Mo in a concentration of about $0.2 \%$ was introduced into steel $\mathrm{B}$, along with Ti and $\mathrm{V}$ microadditions in a concentration of $0.031 \%$ and $0.022 \%$, respectively.

With the aim to determine the phase evolution diagrams under equilibrium conditions and numerical simulation of austenite phase transformations

Table 1. Chemical composition of investigation steels

\begin{tabular}{|c|c|c|c|c|c|c|c|c|c|}
\hline \multirow{2}{*}{ Steel } & \multicolumn{9}{|c|}{ Mass contents, wt \% } \\
\cline { 2 - 12 } & $\mathrm{C}$ & $\mathrm{Mn}$ & $\mathrm{Si}$ & $\mathrm{P}$ & $\mathrm{S}$ & $\mathrm{Mo}$ & $\mathrm{Cr}$ & $\mathrm{Ti}$ & $\mathrm{V}$ \\
\hline $\mathrm{A}$ & 0.165 & 2.00 & 1.11 & 0.014 & 0.020 & - & 0.028 & - & - \\
\hline $\mathrm{B}$ & 0.175 & 1.87 & 1.02 & 0.014 & 0.020 & 0.218 & 0.028 & 0.031 & 0.022 \\
\hline
\end{tabular}


as well as to determine the CCT and TTT curves, the JMatPro software was used (database ver. 11.2) general steel module [31]. The JMatPro software toolkit, which is an acronym for Java-based Materials Properties, was developed by Sente Software Ltd. to predict a wide range of material properties. Some of the many possibilities of this software include numerical simulation of phase transformations and the possibility to determine CCT and TTT curves. The JMatPro software synergistically uses thermodynamics and physical models to describe the phase transformations in steel. In order to explain the CCT and TTT curves, the model proposed in $[19,21,22]$ was applied, based on the equations developed by Hillert and Zener $[15,41]$. The austenitizing temperature of $1100^{\circ} \mathrm{C}$ was taken for theoretical calculations, which is the temperature close to industrial conditions for this type of steel.

\section{RESULTS}

First, theoretical calculations of phase evolution as a function of temperature were performed with the use of the JMatPro software. The diagram of individual phases evolution under equilibrium conditions for the steel containing $0.165 \% \mathrm{C}, 2 \%$ Mn and 1.11\% Si (steel A) is presented in Fig. 1.
The diagram (Fig. 1a) reveals that the austenite is present in a temperature range from about $1472^{\circ} \mathrm{C}$ to approximately $830^{\circ} \mathrm{C}$. The allotropic transformation of austenite into ferrite begins at the temperature of $830^{\circ} \mathrm{C}$, and progresses to the temperature of approx. $680^{\circ} \mathrm{C}$. This means that the $\mathrm{A}_{\mathrm{c} 3}$ temperature, calculated for the analyzed steel, approximates $830^{\circ} \mathrm{C}$, and the $\mathrm{A}_{\mathrm{c} 1}$ temperature amounts to about $680^{\circ} \mathrm{C}$.

The performed calculations also revealed that under equilibrium conditions below the temperature of $700^{\circ} \mathrm{C}$, cementite and $\mathrm{M}_{7} \mathrm{C}_{3}$ and $\mathrm{M}_{23} \mathrm{C}_{6}$ type carbides may precipitate, causing a decrease of austenite stability. The data presented in Fig. 1b (enlarged lower left part of the diagram from Fig. 1a) shows that the temperature of the beginning of cementite precipitation approximates $700^{\circ} \mathrm{C}$, while the process of $\mathrm{M}_{7} \mathrm{C}_{3}$ type carbides precipitation starts at the temperature of $470^{\circ} \mathrm{C}$. Carbides of this type, with their small fraction in microstructure, will be stable up to the temperature of approx. $125^{\circ} \mathrm{C}$, in which a negligible fraction of $\mathrm{M}_{23} \mathrm{C}_{6}$ type carbides can be formed. The conducted analysis revealed that the microstructure of steel A at room temperature may contain insignificant portion of carbides. It should be emphasised that presented phase evolution concerns cooling under equilibrium conditions.

a)

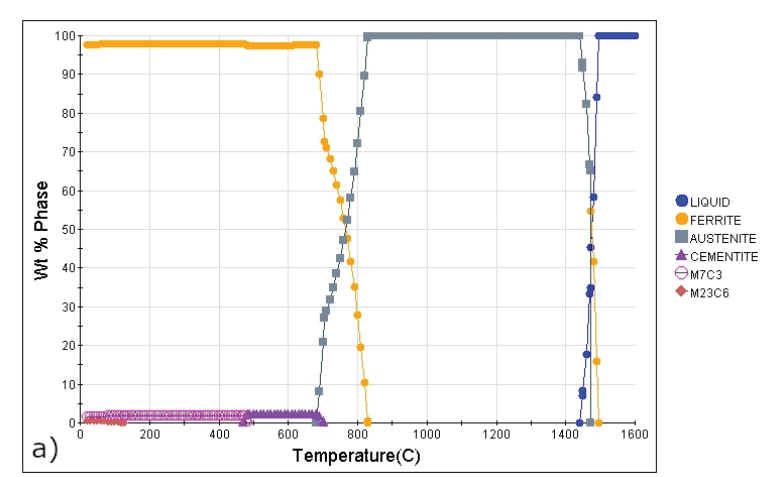

b)

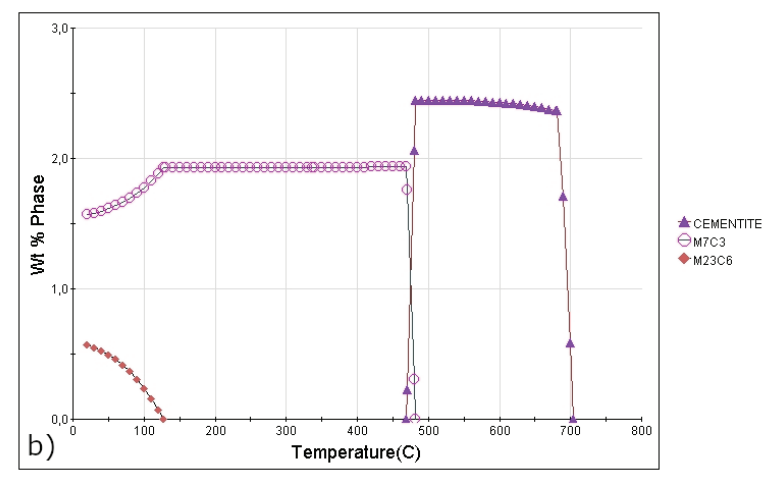

Figure 1. Phase evolution diagram of the steel $\mathrm{A}(0.165 \% \mathrm{C}, 2 \% \mathrm{Mn}$ and $1.11 \% \mathrm{Si})$ in equilibrium conditions: full diagram (a); left bottom magnified part of the diagram (b) 
Figure 2a shows the CCT (Continuous Cooling Transformation) diagram, and Fig. $2 b$ presents the TTT (Temperature Time Transformation) diagram, calculated for steel A for non-equilibrium cooling conditions. The conducted calculations revealed that the $\mathrm{A}_{\mathrm{cl}}$ temperature is slightly higher than the temperature obtained under equilibrium conditions $\left(680^{\circ} \mathrm{C}\right)$ and is equal approx. $704^{\circ} \mathrm{C}$. The reason for this difference is probably decreased diffusion rate in relation to high heating rate [27]. The analysed steel has a relatively low martensitic transformation start temperature $\mathrm{M}_{\mathrm{S}}$, amounting to about $375^{\circ} \mathrm{C}$. Cooling at the rate in a range from $100^{\circ} \mathrm{C} / \mathrm{s}$ to $20^{\circ} \mathrm{C} / \mathrm{s}$ assures obtaining purely martensitic microstructure (Fig. 2a), with calculated hardness equal approx. $408 \mathrm{HV}$. The ferritic transformation starting temperature decreases from approx. $800^{\circ} \mathrm{C}$ for the cooling rate of $0.01{ }^{\circ} \mathrm{C} / \mathrm{s}$ to approx. $520^{\circ} \mathrm{C}$ for the cooling rate of $10^{\circ} \mathrm{C} / \mathrm{s}$. In the investigated steel, bainite was formed at the temperature lower than $490^{\circ} \mathrm{C}$ and/or cooling rate lower than $10^{\circ} \mathrm{C} / \mathrm{s}$. The three-phase microstructure of steel, which includes martensite, bainite and ferrite, occurs in a relatively narrow range of cooling rates, i.e. from $10^{\circ} \mathrm{C} / \mathrm{s}$ to $2^{\circ} \mathrm{C} / \mathrm{s}$. The calculated hardness of the steel, cooled in the analysed cooling rate range, decreases from approx. $400 \mathrm{HV}$ to about 275 HV. Applying a cooling rate of less than $1{ }^{\circ} \mathrm{C} / \mathrm{s}$ results in the formation of pearlite in microstructure. The examined steel A, containing $0.165 \% \mathrm{C}, 2 \% \mathrm{Mn}$ and $1.11 \% \mathrm{Si}$, cooled very slowly, under conditions close to equilibrium will demonstrate ferritic-pearlitic microstructure with hardness of about $180 \mathrm{HV}$.

The results of simulation carried out under isothermal conditions for steel A are presented in Fig. 2b. It results from presented data that the time required to form ferrite nuclei is longer than the time required to start the bainitic transformation. Formation of bainite at the temperature of $450^{\circ} \mathrm{C}$ should start after $10 \mathrm{~s}$ and finish after $200 \mathrm{~s}$. At the temperature of $400^{\circ} \mathrm{C}$, the bainitic transformation should begin after $20 \mathrm{~s}$ and end after $300 \mathrm{~s}$. This means that

a)

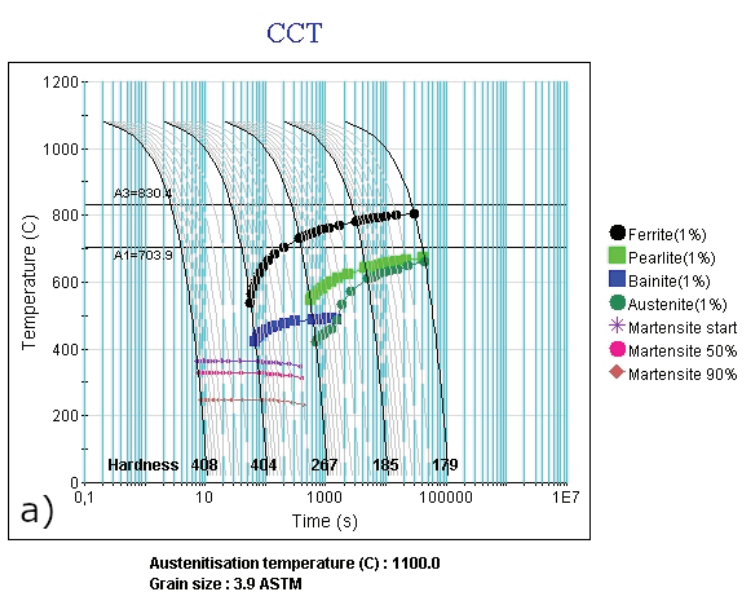

b)

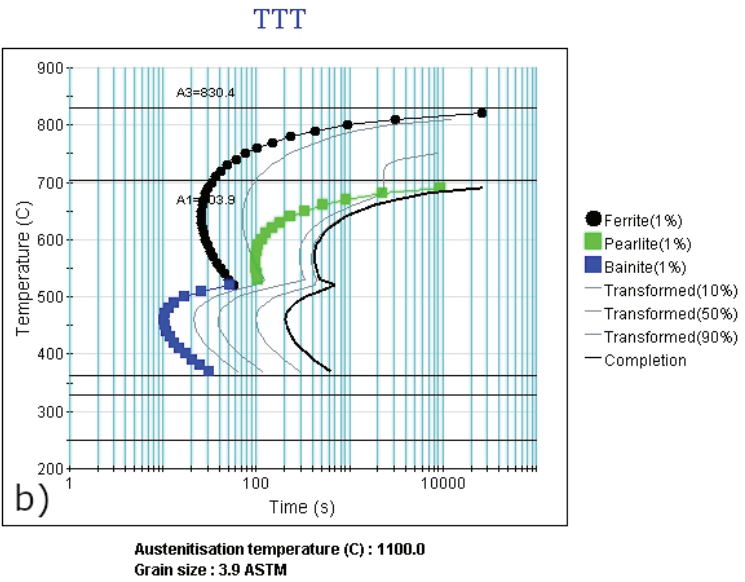

Figure 2. Non-equilibrium diagrams for the steel A (0.165\% C, $2 \% \mathrm{Mn}$ and $1.11 \% \mathrm{Si})$ : CCT diagram (a);

TTT diagram (b) 
the time required to complete the bainitic transformation increases along with temperature decrease.

The diagram presented in Figure 3 shows the changes in the percentage of individual phases as a function of temperature under equilibrium conditions for steel $\mathrm{B}$, to which, apart from $\mathrm{Mn}$ and $\mathrm{Si}$, an addition of Mo at a concentration of $0.22 \%$ was introduced along with $\mathrm{Ti}$ and $\mathrm{V}$ microadditions at a concentration of $0.031 \%$ and $0.022 \%$, respectively. Figure 3 a shows that the crystallisation process of the examined steel begins at the temperature of approx. $1490^{\circ} \mathrm{C}$, and $100 \%$ portion of austenite occurs in a temperature range from about $1440^{\circ} \mathrm{C}$ to about $835^{\circ} \mathrm{C}$. At this temperature, the $\gamma \rightarrow \alpha$ allotropic transformation begins and proceeds to the temperature of approx. $680^{\circ} \mathrm{C}$. The diagram presented in Fig. $3 \mathrm{~b}$ reveals that precipitation of cementite starts at the temperature of approx. $710^{\circ} \mathrm{C}$, and at the temperature of about $565^{\circ} \mathrm{C}$ its anyhow small fraction will be decreasing in favour of the $\mathrm{M}_{7} \mathrm{C}_{3}$ type carbides. Moreover, carbides of the $\mathrm{M}_{6} \mathrm{C}$ type may appear in the microstructure at the temperature lower than $190^{\circ} \mathrm{C}$.

The CCT and TTT diagrams, calculated for steel B for non-equilibrium cooling conditions, are presented in Fig. 4a and Fig. 4b, respectively. The performed calculations revealed that the $\mathrm{A}_{\mathrm{c} 3}$ temperature is approximates $836^{\circ} \mathrm{C}$, and the $\mathrm{A}_{\mathrm{c} 1}^{\mathrm{c} 3}$ temperature is about $710^{\circ} \mathrm{C}$ and it is about $20^{\circ} \mathrm{C}$ higher than the temperature calculated for equilibrium conditions. Furthermore, as expected, the $\mathrm{A}_{\mathrm{cl}}$ temperature determined under non-equilibrium conditions for steel $\mathrm{B}$ is slightly higher than the $\mathrm{A}_{\mathrm{cl}}$ temperature calculated for steel $\mathrm{A}$ under the same conditions. The reason for this is the presence of Mo and also Ti microaddition in steel $\mathrm{B}$, which impact the increase of the $\mathrm{A}_{\mathrm{c} 1}$ temperature. The determined $\mathrm{M}_{\mathrm{S}}$ temperature is equal to $370^{\circ} \mathrm{C}$ and is a few Celsius degrees lower than the $\mathrm{M}_{\mathrm{S}}$ temperature calculated for steel A. A slight decrease in $M_{S}$ temperature of steel $B$ is the result of higher carbon concentration and the presence of molybdenum addition. The examined steel B will obtain purely martensitic microstructure with hardness of approx. $416 \mathrm{HV}$ for the cooling rate in a range from $100{ }^{\circ} \mathrm{C} / \mathrm{s}$ to $10^{\circ} \mathrm{C} / \mathrm{s}$ (Fig. 4a). On the other hand, steel $\mathrm{B}$ will have a microstructure consisting of martensite and bainite in the cooling rate range from $9^{\circ} \mathrm{C} / \mathrm{s}$ to $0.7^{\circ} \mathrm{C} / \mathrm{s}$, with hardness decreasing in this cooling rate range from approx. $415 \mathrm{HV}$ to about $320 \mathrm{HV}$.

What is noteworthy is a distinct shift of the ferritic transformation to the right, towards longer times and, to a lesser degree, also of the pearlitic transformation compared to the position of these transformations on the CCT diagram for steel A. The

a)

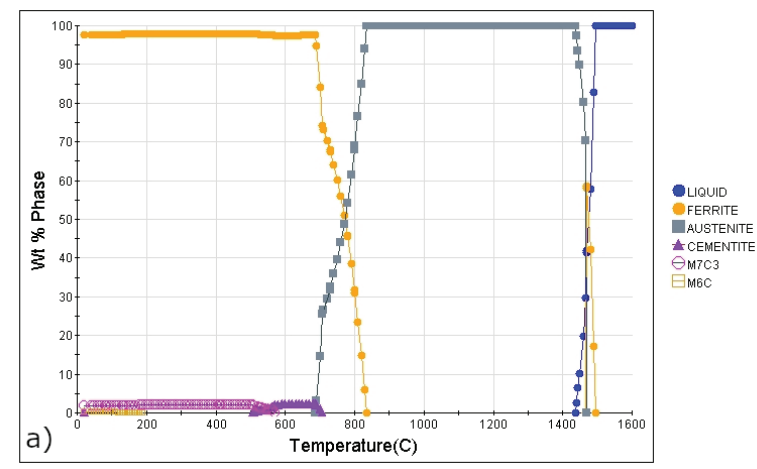

b)

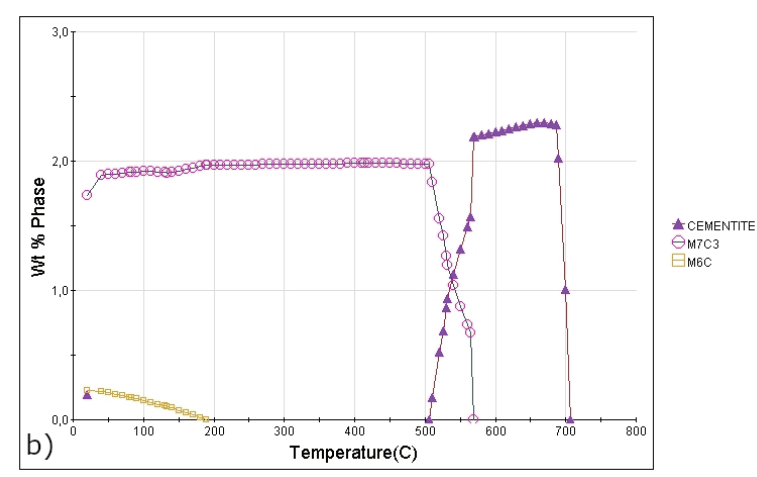

Figure 3. Phase evolution diagram of the steel B $(0.175 \% \mathrm{C}, 1.87 \% \mathrm{Mn}, 1 \% \mathrm{Si}, 0.22 \% \mathrm{Mo}, 0.031 \% \mathrm{Ti}$ and $0.022 \% \mathrm{~V}$ ) in equilibrium conditions: full diagram (a); left bottom magnified part of the diagram (b) 
a)

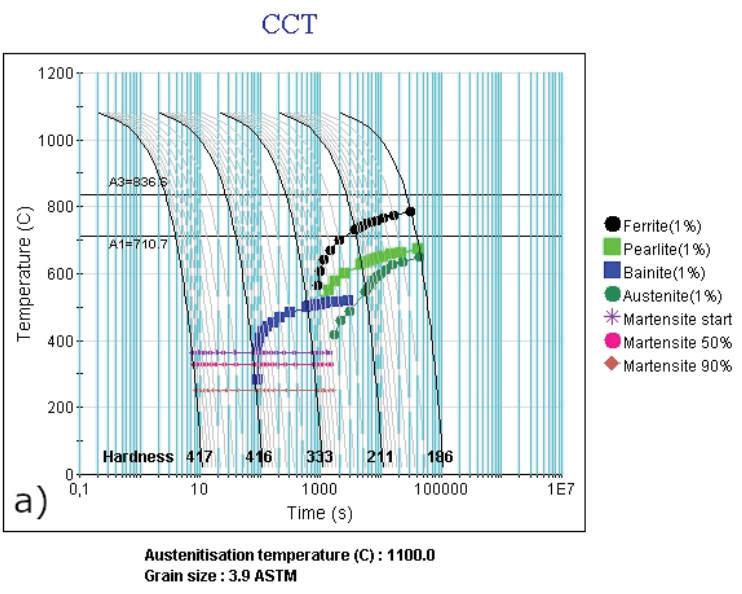

b)

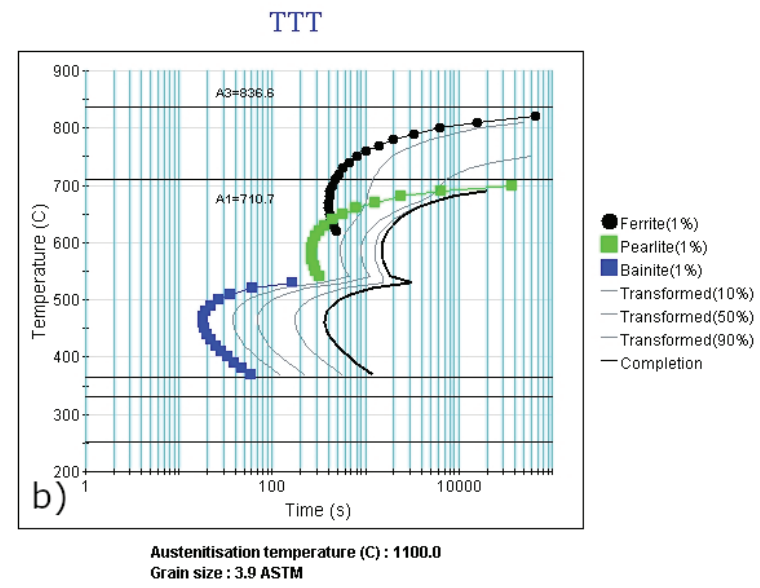

Figure 4. Non-equilibrium diagrams for the steel B $(0.175 \% \mathrm{C}, 1.87 \% \mathrm{Mn}, 1 \% \mathrm{Si}, 0.22 \% \mathrm{Mo}, 0.031 \% \mathrm{Ti}$ and $0.022 \% \mathrm{~V})$ : CCT diagram (a); TTT diagram (b)

temperature of the ferritic transformation start varies from approx. $790^{\circ} \mathrm{C}$ for the cooling rate of $0.01^{\circ} \mathrm{C} / \mathrm{s}$, to about $560^{\circ} \mathrm{C}-$ for the cooling rate of $0.6^{\circ} \mathrm{C} / \mathrm{s}$. In the studied steel B, bainite is formed at the temperature lower than $510^{\circ} \mathrm{C}$ and/or at the cooling rate lower than $10^{\circ} \mathrm{C} / \mathrm{s}$. Comparing the CCT diagrams for both steels, slightly higher hardness values for steel $\mathrm{B}$ can be noted in the entire range of cooling rates.

The simulation results in the form of a TTT diagram under isothermal conditions for steel B are presented in Figure 4b. The data compiled in this figure shows that the bainitic transformation at the temperature of $450^{\circ} \mathrm{C}$ should start after $20 \mathrm{~s}$ and finish after $400 \mathrm{~s}$. This proves that the bainitic transformation bay is shifted towards longer times in relation to its position on the TTT diagram for steel A (Fig. 2b). Even stronger offset to the right in relation to steel A concerns the ferritic and pearlitic transformations. For example, the time to start the ferritic transformation for steel $\mathrm{A}$ at the temperature of $650^{\circ} \mathrm{C}$ approximates $30 \mathrm{~s}$, while it is about
$400 \mathrm{~s}$ for steel B; the end times of this transformation at mentioned temperature are equal to $2000 \mathrm{~s}$ and $5000 \mathrm{~s}-$ for steel A and B, respectively.

The effectiveness of the JMatPro software for predicting the TTT and CCT diagrams has been confirmed in many studies. The calculations of the TTT and CCT diagrams for multiphase steel with similar chemical composition as the analysed steel B were performed in [11]. The obtained results for $0.2 \mathrm{C}-1.5 \mathrm{Mn}-0.5 \mathrm{Si}$ steel with $\mathrm{Nb}$ and Ti microadditions with a concentration of $0.027 \%$ and $0.010 \%$, respectively, were verified by conducting dilatometric tests. The acquired experimental curves were found to be highly consistent with the theoretical curves, both in terms of the determined critical temperatures and the temperature-time ranges of individual austenite phase transformations. The same issues were the subject of research on the newly developed multiphase TRIP steel (0.2C-1.47Mn-0.69Si-1Al) with a microaddition of $\mathrm{Nb}$ in a concentration 
of $0.04 \%$ [40]. The determined TTT diagram for the investigated steel was very consistent with the experimental results. Similarly satisfactory results, concerning the calculation of austenite phase transitions diagrams for multiphase steels experimentally verified - were obtained in the works $[6,16,25,26]$.

\section{CONCLUSIONS}

The application of the JMatPro software allowed determining the evolution of phase components as a function of temperature under equilibrium conditions, numerically simulate austenite phase transformations and to determine the CCT and TTT curves of the newly developed multiphase steels.

The performed simulation of phase evolution as a function of temperature for the equilibrium conditions revealed that the newly developed steels have a similar $\mathrm{A}_{\mathrm{c} 1}$ and $\mathrm{A}_{\mathrm{c} 3}$ temperatures, which approximate $680^{\circ} \mathrm{C}$ and $830^{\circ} \mathrm{C}$, respectively. Under equilibrium conditions, in a temperature range from approx. $700^{\circ} \mathrm{C}$ to approx. $565^{\circ} \mathrm{C}$, cementite may precipitate in the analysed steels. In addition, in lower temperature range, carbides of the $\mathrm{M}_{7} \mathrm{C}_{3}$ and $\mathrm{M}_{23} \mathrm{C}_{6}$ type can be present in the microstructure of steel $\mathrm{A}$ and carbides of the $\mathrm{M}_{7} \mathrm{C}_{3}$ and $\mathrm{M}_{7} \mathrm{C}_{3}$ type in steel $\mathrm{B}$, with their total portion being negligible.

The performed calculations for non-equilibrium conditions revealed that the $\mathrm{A}_{\mathrm{c} 1}$ and $\mathrm{A}_{\mathrm{c} 3}$ critical temperatures for both steels are somewhat higher than those determined for the equilibrium conditions. The reason for this is probably too low diffusion rate in relation to the rapid heating rate. The conducted simulation showed that the interfacial boundaries and temperature-time zones of individual austenite phase transformations for steel B are shifted towards longer times in relation to the austenite phase boundaries for steel A. On the basis of the analysis of the developed CCT and TTT diagrams, a significant delay of diffusion transformations, i.e. ferritic and pearlitic, was stated, a shift to longer times of bainitic transformation, and also a minor decrease of the $\mathrm{M}_{\mathrm{S}}$ temperature. The decisive factor for the shift of austenite phase boundaries in steel B is the presence of Mo and microadditions of Ti and $\mathrm{V}$.

The form of the CCT and TTT diagrams, obtained on the basis of the simulation, indicates the possibility to produce steel forgings with the proposed chemical composition and desired multiphase microstructure. However, it should be taken into account that the models implemented in commercial software include necessary simplifications and the obtained results may contain errors. Therefore, the next stage of the research is to experimentally verify the acquired calculations using the dilatometric method for the newly developed multiphase steels.

\section{REFERENCES}

1. Avrami M. Kinetics of phase change I. General theory. Journal of Chemical Physics 1939; 7: 1103-1112.

2. Badeshia H.K.D.H. Driving force for martensitic transformation in steels. Metal Science 1981; 15: 175-177.

3. Badeshia H.K.D.H. Thermodynamic extrapolation and martensite-start temperature of substitutionally alloyed steels. Metal Science 1981; 15: 178-180.

4. Badeshia H.K.D.H. Thermodynamic analysis of isothermal transformation diagrams. Metal Science 1982; 16: 159-165.

5. Badeshia H.K.D.H., Dimitriu R.C., Forsik S., Pak J.H., Ryu J.H. Performance of neural networks in material science. Materials Science and Technology 2009; 25(4): 504-510.

6. Contreras A., López A., Gutiérrez E.J., Fernández B., Salinas A., Deaquino R., Bedolla A., Saldaña R., Reyes I., Aguilar J., Cruz R. An approach for the design of multiphase advanced high-strength steels based on the behavior of CCT diagrams simulated from the intercritical temperature range. Materials Science and Engineering A 2020; 772: 1-32.

7. De Cooman B.C., Speer J.G. Fundamentals of steel product physical metallurgy. Association for Iron and Steel, Pittsburgh 2011.

8. Diekmann U. Calculation of steel data using JMatPro. International Conference on Recent Trends in Structural Materials, Plzeň, Czech Republic 2012: 1-6.

9. Grajcar A. Stucture of the C-Mn-Si-Al steel formed with strain-induced martensitic transformation. The Silesian University of Technology Publishers, Gliwice 2009, (in Polish).

10. Grajcar A. High strength multiphase steels engineering. The Silesian University of Technology Publishers, Gliwice 2019, (in Polish).

11. Grajcar A., Morawiec M., Zalecki W. Austenite Decomposition and Precipitation Behavior of Plastically Deformed Low-Si Microalloyed Steel. Metals 2018; 8(1028): 1-12.

12. Grajcar A., Woźniak D., Kozłowska A. Non-metallic inclusions and hot-working behavior of advanced high-strengthg medium-Mn steels. Archives of Metallurgy and Materials 2016; 61(2): 811-820. 
13. Gramlich A., Emmrich R., Bleck W. Austenite reversion tempering-annealing of 4 wt.\% manganese steels for automotive forging application. Metals 2019; 9(575): 1-10.

14. Guo Z., Saunders N., Miodownik A.P., Schille J.P. Modelling phase transformations and material properties critical to the prediction of distortion during the heat treatment of steels. International Journal of Microstructure and Materials Properties 2009; 4(2): 187-195.

15. Hillert M. The role of interfacial energy during solid-state phase transformations. Jernkontorets Annaler 1957; 141: 757-789.

16. Isati N., Garcia-Riesco P.M., Jorge-Badiola D., Taheri M., Lopez B., Uranga P. Modelling of CCT diagrams and ferrite grain size prediction in low carbon Nb-Mo microalloyed steels. ISIJ International 2015; 55: 1963-1972.

17. Johnson J., Mehl R. Reaction kinetics in processes of nucleation and growth. Transactions of the AIME 1939; 135: 416-458.

18. Keul C., Wirths V., Bleck W. New bainitic steel for forgings. Archives of Civil and Mechanical Engineering 2012; 12: 119-125.

19. Kirkaldy J.S. Diffusion controlled phase transformation in steel. Scandinavian of Metallurgy 1991; 20: $50-61$.

20. Kirkaldy J.S., Sharma R.C. A new phenomenology for steel it and CCT curves. Scripta Metallurgica 1982; 6(10): 1193-1198.

21. Kirkaldy J.S., Thomson B.A., Baganis E.A. Prediction of multicomponent equilibrium and transformation diagrams for low alloy steels [in:] Doane D.V., Kirkaldy J.S. (Eds.). Hardenability concepts with applications to steel. The Metallurgical Society of AIME, New York 1978, 82-119.

22. Kirkaldy J.S., Venugopolan D. Prediction of microstructure and hardenability in low alloy steels, [In:] Marder A.R. and Goldstein J.I. (eds.). Phase transformations in ferrous alloys. The Metallurgical Society of AIME, Philadelphia 1984, 125-148.

23. Koinstinen D.P., Marburger R.E. A general equation prescribing extent of austenite-martensite transformation in pure $\mathrm{Fe}-\mathrm{C}$ alloys and plain carbon steels. Acta Metallurgica 1959; 7: 59-60.

24. Lee J-L., Badeshia H.K.D.H. A methodology for the prediction of time-temperature-transformation diagrams. Materials Science and Engineering A 1993; 171(1-2): 223-230.

25. Li D., Yan Z., Wang R., Kang Y., Shen L. Effect of Hot- Deformation Processes on Phase Transformation of Low- Alloyed, Multiphase, High- Strength Steel. Steel Research International 2020; 91(11): 1-12.

26. Morawiec M., Grajcar A., Zalecki W., Garcia-Mateo C., Opiela M. Dilatometric study of phase transformation in $5 \mathrm{Mn}$ steel subjected to different heat treatments, Materials 2020; 13(958) 1-15.
27. Navarro-Lopez A., Sietsma J., Santofimia M.J. Effect of prior a thermal martensite on the isothermal

28. transformation kinetic below Ms in a low-C high-Si steel. Metallurgical and Materials Transactions A 2016; 47(3): 1028-1039.

29. Opiela M. Thermomechanical treatment of Ti-Nb-V-B microalloyed steel forgings. Materiali in Tehnologije 2014; 48(4): 587-591.

30. Pernach M., Pietrzyk M. Numerical solution of the diffusion equation with moving boundary applied to modelling of the austenite-ferrite phase transformation. Computational Materials Science 2008; 44: 783-791.

31. Saunders N., Guo Z., Li X., Miodownik A.P., Schillé J.P. Using JMatPro to model materials properties and behavior. The Journal of The Minerals, Metals \& Materials Society 2003; 55: 60-65.

32. http://www.sentesoftware.co.uk/biblio.html

33. Sugimoto K., Hojo T., Kobayashi J. Critical assessment of TRIP-aided bainitic ferrite steels. Materials Science and Technology 2017; 33(17): 2005-2009.

34. Sugimoto K., Hojo T., Mizuno Y. Torsional fatigue strength of newly developed case hardening TRIP-aided steel. Metals 2017; 7(375): 1-13.

35. Sugimoto K., Hojo T., Srivastava A.K. An Overview of fatigue strength of case-hardening TRIP-aided martensitic steels. Metals 2018; 8(355): 1-19.

36. Sugimoto K., Hojo T., Srivastava A.K. Low and medium carbon advanced high-strength forging steels for automotive applications. Metals 2019; 9(1263): 1-14.

37. Timokhina I.B., Hodghson P.D., Pereloma E.V. Effect of alloying elements on the microstructure-property relationship in thermomechanically processed C-Mn-Si TRIP steels. Steel Research 2002; 73: 274-279.

38. Traint S., Pichler A., Sierlinger R., Pauli H., Werner E.A. Low-alloyed TRIP-steels with optimized strength, forming and welding properties. Steel Research 2006; 77: 641-649.

39. Trzaska J. Empirical formulae for the calculation of austenite supercooled transformation temperatures. Archives of Metallurgy and Materials 2015; 60(1): 181-185.

40. Trzaska J., Dobrzański L.A. Modelling of CCT diagrams for engineering and constructional steels. Journal of Materials Processing Technology 2007; 192-193: 504-510.

41. Wang C., Ding H., Cai M., Rolfe B. Multi-phase microstructure design of a novel high strength TRIP steel through experimental methodology. Materials Science and Engineering A 2014; 610: 436-444.

42. Zener C. Kinetics of the decomposition of austenite. Transaction of the Metallurgical Society of AIME 1946; 167: 550-559.

43. Zhang J.C., Mo C., Li D., Li Y. Modeling of phase transformation of plain carbon steels during continuous cooling. Journal of Materials Science and Technology 2003; 19(3): 262-264. 